\title{
VIRTUAL LEODIUM: FROM AN HISTORICAL 3D CITY SCALE MODEL TO AN ARCHAEOLOGICAL INFORMATION SYSTEM
}

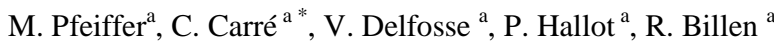

${ }^{a}$ Geomatics Unit, Department of Geography, University of Liege, Belgium

michelle.pfeiffer@ulg.ac.be, cyril.carre@ulg.ac.be, vincent.delfosse@ulg.ac.be, p.hallot@ulg.ac.be, rbillen@ulg.ac.be

\begin{abstract}
KEY WORDS: Scale model, 3D City Model, 3D Modeling, Spatio-temporal database, Archaeological Information Systems,
\end{abstract} Cultural Heritage

\begin{abstract}
:
Virtual Leodium is an interdisciplinary project aiming to develop an archaeological information system based on a city scale model. The first part of the paper describes current project's achievements; the general methodology and the workflow of the project, namely the production and the modelling of archaeological data; the prototype functions of the ad hoc developed archaeological information system. The second part of the paper presents our new Virtual Leodium archaeological information modelling approach, which aims at consider, in a more comprehensive way, the complexity of archaeological information.
\end{abstract}

\section{INTRODUCTION}

Over the last centuries, 3D city scale models have been created all over Europe. They were originally built with the main purpose of elaborating military operations (e.g. "Plans-reliefs' collection" requested in 1668 by Louis XIV, King of France) (de Montalembert, 2012; Faucherre, 1996). In the early XX $X^{\text {th }}$ century, new scale models have been produced for cultural heritage and urban planning purposes (Billen et al., 2009; Laroche et al., 2011; Sedlacek et al., 2012). In both cases, they represent snapshots of cities' past and are consequently extremely rich 'document information'.

Over the last decade, some of these scale models have been digitalized and virtual 3D models have been constructed (Chevrier et al., 2010; Google, 2012; Jacquot, 2010; Kriouche, 2011; Nguyen, 2010; Pitard, 2011). Very few of them are going beyond visualization; they only represent textured geometric models without any other kind of associated knowledge or information.

Since 1907, the University of Liege has housed among its art collection a scale model representing the city of Liege around 1730. Due to the conservation and preservation conditions, the access to this master piece has been restricted for a long time. In 2009, the Virtual Leodium (Billen et al., 2009; Billen et al., 2012) project was launched promoting an access to a larger public and assuring the conservation of the scale model. The acquisition of the scale model by the technology of 3D laser scanning was the starting point of this interdisciplinary project gathering skills in geomatics, archaeology and physics. The main goal of this project is to develop an urban archaeological information system. This development responds to the increasing needs of archaeologists and historians for a powerful set of tools for managing, archiving and exploring large archaeological data sets in order to yield new elements responding to archaeological problems (Burrough and McDonnell, 1998). The final system is intended for several uses; the study of the scale model itself (for historians and archaeologists) and the study of the evolution of the city of Liege (historians, urban planners...), the improvement of communication about the historical city through 3D virtual scenes available on Internet or museums.

The project is only partially funded; up to now most of the work has been carried out by researchers and students. Since 2011, an active cooperation has been established with the CERMA ${ }^{* *}$ and IRCCYN $^{* * *}$ teams from the Ecole Centrale Nantes, France, which work on the same topic through their project Nantes 1900 .

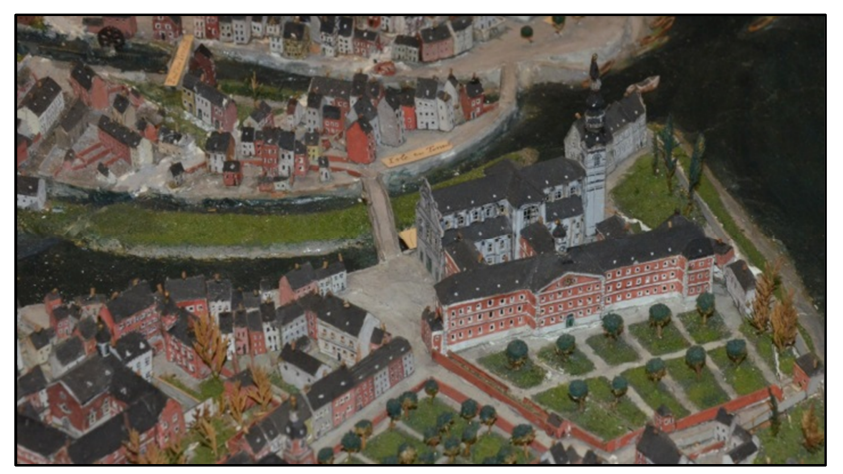

Figure 1. Photography of Gustave Ruhl's scale model representing the City of Liege around 1730

The first part of the paper exposes the Virtual Leodium project; we explain the methodology and the workflow of the project namely the acquisition of the archaeological data as well as the

\footnotetext{
* Corresponding author

** Centre de recherche méthodologique d'architecture (CERMA), Ecole Centrale de Nantes, http://www.cerma.archi.fr

${ }^{* * * *}$ Institut de recherche en communication et cybernétique de Nantes (IRCCYN), Ecole Centrale de Nantes, http://www.irccyn.ec-nantes.fr
} 
3D data. Then, we sketch the current archaeological information system prototype. The second part is dedicated to the latest improvements of the archaeological data model. Finally, we raise perspectives and future developments of the project.

\section{CURRENT STATE OF VIRTUAL LEODIUM PROJECT}

\subsection{Archaeological input data}

The scale model, entitled "La noble Cité de Liège en 1730", was completed in 1911 and represents the city of Liege around 1730 (scale of $1 / 1200$, dimension of $1 \mathrm{~m}$ by $1 \mathrm{~m}$ ). His author, Gustave Ruhl, had studied the law and was a passionate amateur of archaeology. It took him more than ten years to realize this master piece of art. With the death of Gustave Ruhl, nearly all of his numerous scale models, as well as a collection of more than 600 documents including notes, plans, sketches, drawings, and photographs, joined the art collection of the University of Liege (Pfeiffer, 2011). In Virtual Leodium project, the scale model is considered as an archaeological data by itself, as well as all the related documents provided by Ruhl and other documents related to the city structure in the XVIII ${ }^{\text {th }}$ century. Owing to the abundance of archaeological data, the research project has been started out on a representative part of Ruhl's collection.

\subsection{D data acquisition}

The scale model has been scanned in several pieces, through several positions (vertical, front, back, left side, right side) using an optical inspection technique (Billen et al., 2009). The result is a cloud of $3 \mathrm{D}$ points composed of 650 individual scans. These scans have been cleaned and merged with the 3D software Geomagic Studio ${ }^{*}$, the final output is a digital surface model. The 3D objects reconstruction is based on the 3D graphics software Maya ${ }^{* *}$ by using the digital surface model and photos of the scale model. Every building face has been photographed. The resulting images have been rectified with Photoshop $^{* * * *}$ and used as draping textures (Figure 2). The data processing flow is sketched in Figure 3.

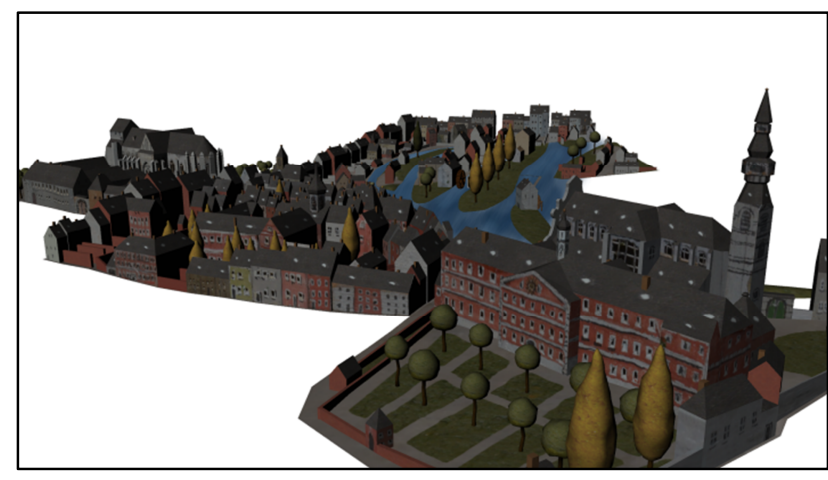

Figure 2. Snapshot of the 3D reconstruction in Maya. This subset of the 3D model shows the textured building modelled from the $3 \mathrm{D}$ point cloud.

\footnotetext{
*Geomagic, Geomagic Studio, 3D software, http://www.geomagic.com/en/products/studio/overview/

** Autodesk, Autodesk Maya, 3D software, http://www.autodesk.com/products/autodeskmaya/overview/

*** Adobe System, Adobe Photoshop, graphics editing program, http://www.adobe.com/en/products/photoshop.html
}

The 3D reconstruction is still in process. Currently, about $20 \%$ of the entire model has been modelled in 3D.

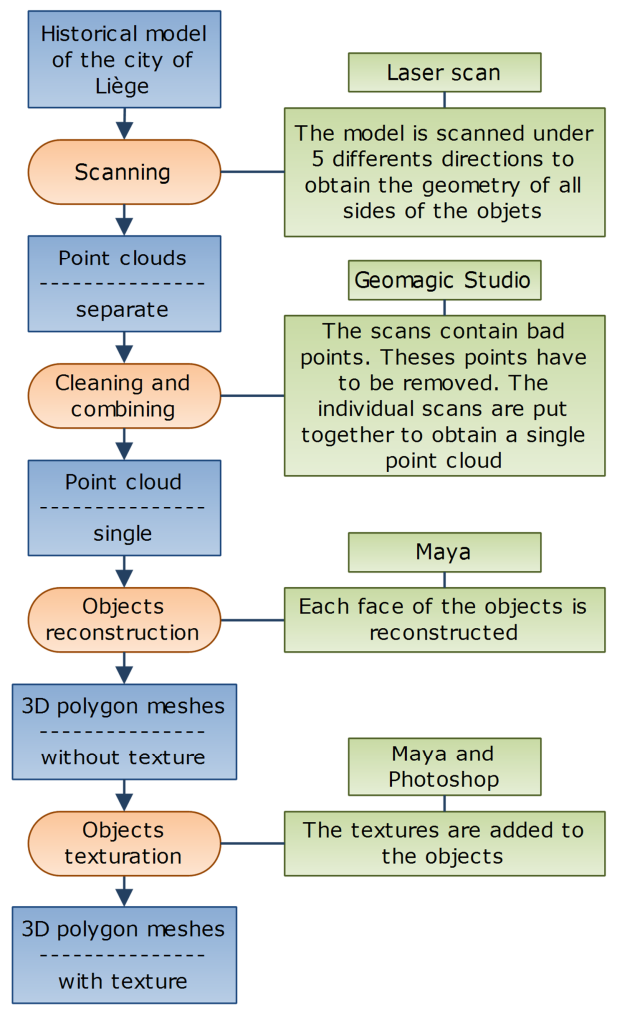

Figure 3. 3D data acquisition and object reconstruction workflow

\subsection{Virtual Information System}

2.3.1 Information model: An ad-hoc model has been developed, gathering both geometrical and historical information. It is partially based on the urban data standard CityGML (Gröger et al., 2012), mainly for interoperability purposes. It can be seen as a contribution to an archaeological extension of the CityGML. The interested reader can refer to (Billen et al., 2012; Hervy et al., 2012) to find a deeper description of the first version of the Virtual Leodium information model.

2.3.2 System functionalities: The application is developed in Java and relies on the ArcGIS Engine ${ }^{* * * *}$. It provides database access functions as well as $3 \mathrm{D}$ visualization via the ArcScene API. Spatial and semantic data are stored in an ArcGIS Geodatabse. The UML data model has been mapped into this relational database.

The archaeological information system is based on client-server architecture. The client interface is divided in two parts (see Figure 4). The first one allows the user to visualize and navigate in a $3 \mathrm{D}$ world. The second one allows the user to browse a collection of semantic information. It can show the historical sources themselves, or any specific information about the building, like its function or the architect's name. Both parts are fully synchronized. Selecting a building in the 3D scene will display its semantic information, and browsing the semantic

**** Esri, ArcGIS Engine, collection of GIS components and developer http://www.esri.com/software/arcgis/arcgisengine 
information will highlight the relevant $3 \mathrm{D}$ elements in the scene. Also, by selecting a specific building or building element in the semantic view, its geometric 3D representation will be displayed, immersed in a 3D scene.

Multiple 3D versions of the same building element are supported; this allows the handling of ambiguity or incompleteness (see Figure 5). In the context of archaeological research, we can mix different versions from multiple historical representations of a particular building. This produces new original 3D scenes based on decisions motivated by the historical documents archived in the system. Currently, the system manages iconographic and written sources.

The prototype has been realized in a showcase purpose. Our research focuses now on the development of a more appropriate urban archaeological model. We plan to use open sources software and platforms for our next prototype.

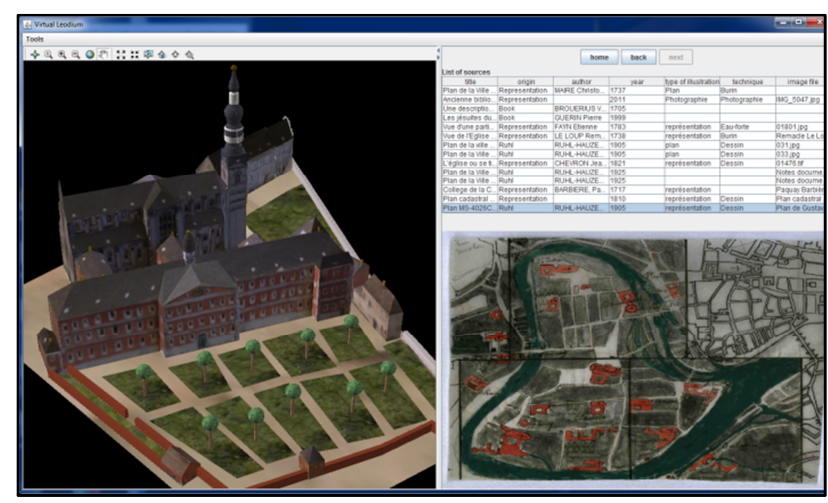

Figure 4. A snapshot of the current version of the Virtual Leodium prototype

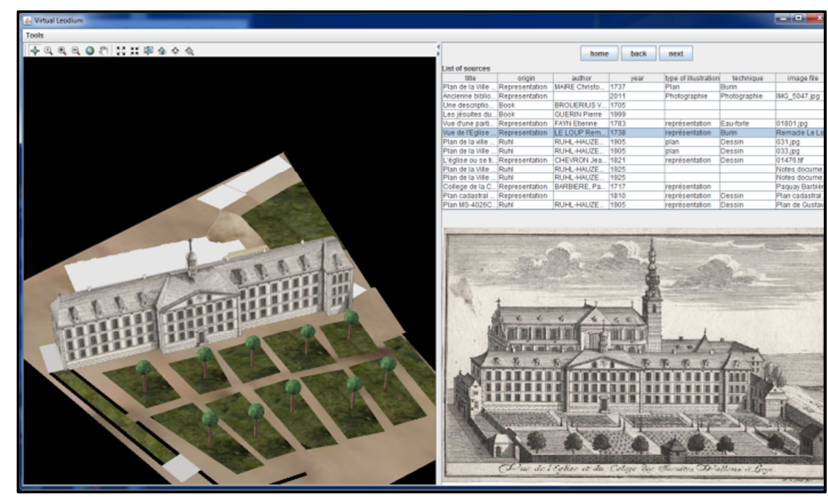

Figure 5. Remacle Le Loup's version of a building facade is displayed in place of Ruhl's version

\section{ARCHAEOLOGICALLY BASED INFORMATION MODEL}

The validation of the first version of the prototype shows that the information model needs to be improved. It has been designed originally more like a CityGML extension aiming to encompass archaeological information complexity, but indeed it seems to be inefficient to manage all objects' versions and possible representations. We believe that the new model should be more archaeology centred; a core archaeological urban data model with CityGML capabilities. In the following section, we discuss the concepts of object's identity, event management, information imperfection we wish to handle in our future information system.

\subsection{Historical object and identity}

The archaeological information is characterized by its spatiality, temporality, multimodality and inherent imperfection (de Runz, 2008). We have based the identity of our archaeological object on the definition proposed by Rodier, which includes necessarily the temporal, functional and spatial entities

(Galinié et al., 2004; Rodier et al., 2011; Rodier et al., 2012). This definition is used to record and analyze urban organizations and changes over long time spans. It fits well with our context of the urban scale model. Moreover, Lefebvre (Lefebvre, 2008) has demonstrated that this definition was usable in real case.

However, we deviate from the Rodier's model especially on two points. The first one concerns the definition of the historical object. For Rodier, a change of time, function, or spatiality leads necessarily to a change of identity (Rodier et al., 2011).

Instead of Rodier's definition, we prefer the definition proposed by Hornsby (Hornsby and Egenhofer, 2000); a change of the constituents of the object does not necessary lead to an identity change of the objet. An object is defined by a set of constituents assembled in a certain way; you can add or remove some of them without changing the identity. The second one is that Rodier's model does not handle the imperfect nature of archaeological data. Indeed, the identity is defined by three components: time, function, spatiality, if one of these components is missing the object can difficulty be defined (de Runz, 2008). We are currently working on a system providing more flexibility in terms of "object identity".

\subsection{Event management}

Depending on the field of study, several definitions and uses of event can be mentioned. One of them comes from the world of computer science (database, file system, programming language...). In this case, the event is used to record change between two different states of the system. This approach is used in managing change tracking of geographic data (Worboys and Hornsby, 2004; Worboys, 2001). A second approach is more cognitive, the event is used as a phenomena descriptor. It is used to link people, places and objects together. This interpretation is found in different models and ontologies made for different purposes like historical database, libraries ... for example CIDOC CRM (Crofts et al., 2011), ABC Ontology (Lagoze and Hunter, 2006), EventsML-G2 (IPTC, 2013), LODE (Shaw et al., 2009), etc.

We choose to base our model on the computational vision of event. In a near future, we plan to extend it by using ontologies.

\subsection{Imperfection}

The first source of imperfection comes from the fact that humans have an abstracted view of the world. The human brain conceptualizes the environment and everyone has their own understanding of the reality (Shu et al., 2003). The second source of imperfection is due to acquisition techniques (total station, 3D scanner, photography...) and to restrictions imposed by computer systems.

To support the many possibilities of imperfection, our approach is mainly based on the work of De Runz (de Runz, 2008; Desjardin et al., 2012) especially focusing on archeology objects. De Runz distinguishes four different (but non- 
exhaustive) types of imperfection of the archaeological data, namely: the uncertainty, the imprecision, the ambiguity and the incompleteness.

Temporal imperfection has been studied in depth too and several researches are dedicated to (Pani and Bhattacharjee, 2001). One of our priority is to handle temporal imperfection; we plan to use a time model like MADS (Parent et al., 2006), OWL-Time (Hobbs and Pan, 2006), ISO standards (ISO, 2002), and event ontology mentioned above. We also wish to investigate solutions like multiples time-spans with fuzzy bounds (Green, 2008; Holmen and Ore, 2009; Matoušek, 2012).

During the study of the Ruhl scale model, we were confronted to multiple representations issues; various sources providing different representations of the same building. In order to manage ambiguity of spatial information, we have developed the concept of 'version'. For example, one building frontage has two possible representations: one "Version" was represented by Ruhl (see Figure 4) and the second by a drawing of Remacle Le Loup (see Figure 5). In the Future, we wish to integrate others aspect of spatial imperfection. Many researches have already been explored this field of study, some examples are (Duckham and Sharp, 2005; Shu et al., 2003).

\subsection{Model proposition}

According to the concepts we outlined above, this section presents the archaeological data model proposition (see Figure 6 ). The historical object is the basic unit of our model and is placed at the center of the system. The historical objet corresponds to the definition of identity exposed in section 3.1 namely spatiality, temporality and function. These three components are not specific to the archaeological object. Indeed, they are used to describe the objects of today's urban data models like CityGML. CityGML defines the building object by the "usage" (functional component), "the date of creation and destruction" (temporal component) and "the geometry" (spatial component). The CityGML model does not fully correspond to the needs expressed by archaeologists. Moreover, CityGML does not support complex building modifications or fuzzy data sets. It is not suitable for studying urban dynamics in a long term.

In our model, the "City Object" and its subtypes are taken from CityGML. Each "City Object" inherits from the class "Historical Object" and becomes itself an historical object. The geometry comes from the CityGML, the "Building Element", the "Plan Cover", "Solidary Vegetation" and "Land Use" are directly link to their respective geometry. In order to ensure the readability, these relations are hidden in the UML model (see Figure 6). The model integrates the three different types of sources usually considered in archaeology: iconographic sources, written sources and the archaeological remains (Rodier et al., 2011). The "Source" stores all historical documents which may have multiple and sometimes contradictory interpretations. A "Source" could be related to a building, a building element or a group of buildings ("City Object Group"), in order to document the proper object. A source can describe the "Historical Object" itself or inform about a modification owing to its relation to the "Modification Event". The origin of the event is documented by the "Source".

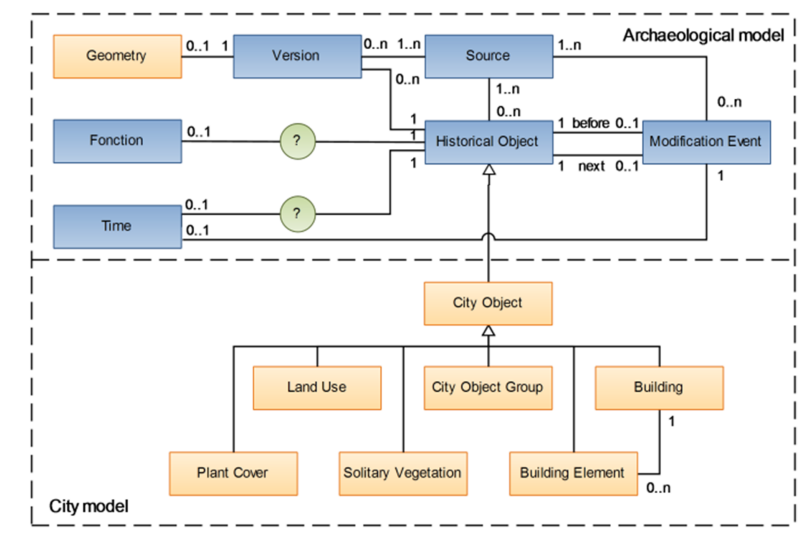

Figure 6. Virtual Leodium information UML model

One characteristic of this model is the possibility to manage the archaeological object dynamics, with the notion of "Modification Event". Event-based modeling allows keeping the tracks of the evolutions of an archaeological object. Each modification on the "Historical Object" is recorded.

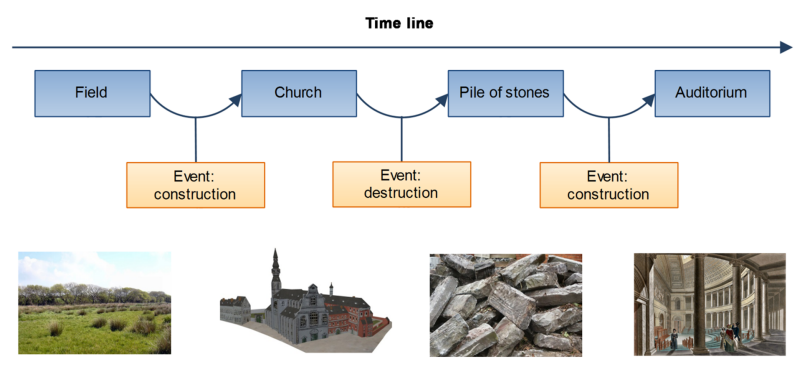

Figure 7. An example of "Modification events"

The Figure 7 shows an example of using the «Modification Event » notion on a specific location. It illustrates the evolution of the area where the Academic Auditorium of the University of Liege is currently standing. Originally, there was a field with no construction, and then the Jesuits built a church. The church was demolished and the Academic Auditorium was built afterwards.

This new model is intended to integrate and partly manage imperfect archaeological data. To manage the incompleteness of the object, the presence of the three components (geometry, function, time) has been made optional. We have integrated the notion of "Version", which allows us to represent multiple spatial representations for the same object (and which was present in the former Virtual Leodium model). Note that we wish to extend this concept of version to the function and the temporality of the historical object.

The work on the object identity definition is in progress. Accordingly we do not detail further this concept in this paper. Up to now the definition of factors triggering the change of an object's identity is left free to the end-user encoding the data.

\section{CONCLUSIONS AND FUTURE DEVELOPMENTS}

We have presented first the current achievements of the Virtual Leodium Project by explaining the methodology, the workflow and the development of the archaeological data model and by describing the prototype architecture and capabilities. 
In the long term Virtual Leodium project aims to develop an archaeological information system dedicated to urban archaeology. Although the proposed data model is still in progress, we identified several ways providing a useful framework for archaeological information modeling. Nevertheless, some improvements are necessary regarding to the concept of identity, the management of archaeological data imperfection and event. The next research step will be to get rid of the proprietary software and base our system as much as possible on international standards.

This new modelling approach is not only dedicated to the project Virtual Leodium or urban archaeology, but more generally to urban information systems (past / present / future).

Beside the improvement of the data model, we continue the reconstruction of $3 \mathrm{D}$ objects in order to complete the entire $3 \mathrm{D}$ city and also to integrate more related archaeological data from the Ruhl's collection. Note that the mapping of the 3D historical objects to the Belgian national coordinate system is in progress. We also continue our cooperation with the CERMA and IRCCYN teams with a view of the development of an automatic building reconstruction and segmentation method.

\section{ACKNOWLEDGEMENTS}

Regarding the Virtual Leodium project, the authors would like to thank the Artistic Collections of the University of Liege and the Cultural Heritage Centre of the University of Liege libraries network, respectively the owner and curator of the Gustave Ruhl scale model, for making accessible this wonderful piece of art. This research has benefited from the SpatioData project funded by the Walloon Region (WIST3 $\mathrm{N}^{\circ} 1017094$ ).

\section{REFERENCES}

\section{References from Journals:}

Desjardin, E., Nocent, O., de Runz, C., 2012. Prise en compte de l'imperfection des connaissances depuis la saisie des données jusqu'à la restitution 3D. Archeologia e Calcolatori supplemento 3, pp. 385-396.

Duckham, M., Sharp, J., 2005. Uncertainty and geographic information: Computational and critical convergence. Representing GIS, p. 113-124.

Faucherre, N., 1996. Note sur Louvois et les plans en relief. Histoire, économie et société 15, pp. 123-124.

Galinié, H., Rodier, X., Saligny, L., 2004. Entités fonctionnelles, entités spatiales et dynamique urbaine dans la longue durée. Histoire \& mesure 19, pp. 223-242.

Hornsby, K., Egenhofer, M.J., 2000. Identity-based change: a foundation for spatio-temporal knowledge representation. International Journal of Geographical Information Science 14, pp. 207-224.

Lagoze, C., Hunter, J., 2001. The ABC Ontology and Model. Journal of Digital Information 2, pp. 478-496.

Pani, A.K., Bhattacharjee, G.P., 2001. Temporal representation and reasoning in artificial intelligence: A review. Mathematical and Computer Modelling 34, pp. 50-80.
Worboys, M.F., 2001. Modelling changes and events in dynamic spatial systems with reference to socio-economic units. Life and Motion of Socio-Economic Units, pp. 129-138.

\section{References from Books:}

Burrough, P.A., McDonnell, R., 1998. Principles of geographical information systems. Oxford university press, Oxford, United Kingdom.

Rodier, X., Barge, O., Saligny, L., Nuninger, L., Bertoncello, F., 2011. Information spatiale et archéologie, Errance, Paris, France.

Shaw, R., Troncy, R., Hardman, L., 2009. Lode: Linking open descriptions of events, The Semantic Web. Springer, pp. 153167.

Worboys, M., Hornsby, K., 2004. From Objects to Events: GEM, the Geospatial Event Model, Geographic Information Science. Springer Berlin Heidelberg, pp. 327-343.

\section{References from Other Literature:}

Billen, R., Blain, P., Donneau, O., Habraken, S., Renotte, Y., Van Ruymbeke, M., 2009. Virtual model of the city of Liège in the eighteen century - "Virtual Leodium", International 3D Stereo Film and Technology Festival (3D Stereo MEDIA). Liège, Belgium.

Billen, R., Carré, C., Delfosse, V., Hervy, B., Laroche, F., Lefevre, D., Servieres, M., Van Ruymbeke, M., 2012. 3D historical models: the case studies of Liege and Nantes, COST Action TU801: Semantic Enrichment of $3 D$ city models for sustainable urban development - Workshop. Nantes, France.

Chevrier, C., Jacquot, K., Perrin, J., 2010. 3D modelling of a town scale model, In 3rd International Conference Dedicated on Digital Heritage, EuroMed 2010. Lemessos, Cyprus.

Crofts, N., Doerr, M., Gill, T., Stead, S., Stiff, M., 2011. Definition of the cidoc conceptual reference model version 5.04.

de Runz, C., 2008. Imperfection, temps et espace : modélisation, analyse et visualisation dans un SIG archéologique, France.

Green, C., 2008. It's about Time: Temporality and Intra-Site GIS, Computer Applications and Quantitative Methods in Archaeology (CAA). Proceedings of the 37th International Conference, Budapest, Hungary.

Gröger, G., Kolbe, T.H., Nagel, C., Häfele, K.-H., 2012. OGC City Geography Markup Language (CityGML) Encoding Standard, Open Geospatial Consortium?

Hervy, B., Billen, R., Laroche, F., Carré, C., Servieres, M., Van Ruymbeke, M., Tourre, V., Delfosse, V., Kerouanton, J.-L., 2012. A generalized approach for historical mock-up acquisition and data modelling: towards historically enriched 3D city models, Utility of $3 D$ City Models - European COST Action TU0801. EDP Sciences, Nantes, France.

Holmen, J., Ore, C.-E., 2009. Deducing event chronology in a cultural heritage documentation system, Making History Interactive. Computer Applications and Quantitative Methods 
in Archaeology (CAA). Proceedings of the 37th International Conference., Williamsburg, United States of America.

ISO, 2002. ISO 19108:2002 Geographic information Temporal schema, TC 211 Geographic information/Geomatics.

Jacquot, K., 2010. Restitution des Plans-Reliefs datant du XIXe siècle, Nancy, France.

Kriouche, A., 2011. Modélisation des bâtiments du plan-relief de Toul datant du XIXe siècle, Nancy, France.

Laroche, F., Servieres, M., Lefevre, D., Kerouanton, J.-L., 2011. Where virtual enhances physical mock-up: A way to understand our heritage, Mixed and Augmented Reality-Arts, Media, and Humanities (ISMAR-AMH), 2011 IEEE International Symposium On. IEEE, Basel, Switzerland.

Lefebvre, B., 2008. La formation d'un tissu urbain dans la Cité de Tours : du site de l'amphithéâtre antique au quartier canonial (5e-18e s.), France.

Matoušek, K., 2012. Temporal ontology for representation and reasoning about uncertain historical time periods, Ecole thématique MoDys 2012, Fréjus, France.

Nguyen, M.H., 2010. Modélisation du Plan-Relief de Toul, Nancy, France.

Parent, C., Spaccapietra, S., Zimányi, E., 2006. Conceptual Modeling for Traditional And Spatio-Temporal Applications: The MADS Approach. Springer Berlin Heidelberg.

Pfeiffer, M., 2011. Approche critique de «La noble Cité de Liège en 1730 » à travers l'étude du collège des Jésuites en Île. Évaluation par application d'un outil archéomatique.

Pitard, B., 2011. Modélisation paramétrique de plans-reliefs datant du XIXe siècle, Nancy, France.

Rodier, X., Saligny, L., Lefebvre, B., 2012. La modélisation de l'information spatio-temporelle pour l'étude de la fabrique urbaine sur le temps long, Ecole thématique MoDys 2012, Fréjus, France.

Sedlacek, D., Burianek, J., Zara, J., 2012. 3D Reconstruction Data Set - The Langweil model of Prague (Technical Report), in: Secondary Sedlacek, D., Burianek, J., Zara, J. (Eds.), Secondary 3D Reconstruction Data Set - The Langweil model of Prague (Technical Report).

Shu, H., Spaccapietra, S., Parent, C., Sedas, D.Q., 2003. Uncertainty of Geographic Information and Its Support in MADS, 2nd International Symposium on Spatial Data Quality, Hong Kong, China.

References from websites:

de Montalembert, G., 2012. La France miniature, passion royale. Le Figaro http://www.lefigaro.fr/lefigaromagazine/2011/12/30/0100620111230ARTFIG00458-la-france-miniature-passionroyale.php (25 Mar. 2013).
Google, C.I., 2012. La France en relief - Des plans-reliefs détaillés transformés en modèles 3D. Google http://www.google.com/intl/fr/culturalinstitute/about/francerelie f.html (27 Mar. 2013).

Hobbs, J.R., Pan, F., 2006. Time Ontology in OWL. W3C Working Draft, 27 September 2006. World Wide Web Consortium http://www.w3.org/TR/owl-time/ (14 Mar. 2010).

IPTC, 2013. EventsML-G2. International Press Telecommunications Council http://www.iptc.org/site/Home/ (25 Mar. 2013). 